\title{
Statistical Methods in Kansei Engineering: a Case of Statistical Engineering
}

\author{
Lluís Marco-Almagro (lluis.marco@upc.edu) \\ Xavier Tort-Martorell Llabrés (xavier.tort@upc.edu) \\ Department of Statistics and Operations Research \\ Universitat Politècnica de Catalunya - BarcelonaTech
}

\begin{abstract}
:
Kansei Engineering (KE) is a technique used to incorporate emotions in the product design process. Its basic purpose is discovering in which way some properties of a product convey certain emotions in its users. It is a quantitative method, and data is typically collected using questionnaires. Japanese researcher Mitsuo Nagamachi is the founder of Kansei Engineering. Products where KE has been successfully applied include cars, phones, packaging, house appliances, clothes or websites, among others.

Kansei Engineering studies typically follow a model with three main steps: (1) spanning the semantic space: defining the responses, those emotions that will be studied; (2) spanning the space of properties: deciding on the technical properties of the products that can be freely changed and that might affect the responses (factors in a factorial design) and (3) the synthesis phase, where both spaces are linked (that is, how each factor affects each response is discovered).

The procedure resembles that of an experimental design in an industrial context. However, practitioners of KE are hardly ever statisticians. Many well-known statistical methods are commonly used in KE, such as principal component analysis and regression analysis, but the techniques are sometimes misused. Furthermore, the discipline could benefit from a more extensive use of statistical methods (some of them of higher complexity, but easily implemented with existing statistical software).

Statistics is thus essential in Kansei Engineering. But if statisticians do not enter into this arena, others will do, as there is a real need and interest in the topic. Kansei Engineering is a good area of application of what Roger W. Hoerl and Ron Snee call statistical engineering: focusing not in advancement of statistics - developing new techniques, fine tuning existing ones - but on how current techniques can be best used in a new area. The aim of this paper is presenting the fundamentals of Kansei Engineering while giving a practical example of statistical engineering in a promising field.
\end{abstract}

Keywords: Kansei engineering, statistical engineering, cluster analysis, factorial designs, ordinal logistic regression, data visualization 
Statistical Methods in Kansei Engineering: a Case of Statistical Engineering.

Lluís Marco-Almagro, Xavier Tort-Martorell Llabrés

\section{An Introduction to Kansei Engineering}

Users of products and services - all of us - are becoming more and more demanding. In this beginning of the XXI century, we do not only want products that work well and satisfy our needs, we also want products that we like. When customers are questioned on what they want, a list of needs normally referring to functionality is obtained. Designers and engineers can translate this voice of the customer into technical parameters, so that the product fulfills those needs. However, customers do not usually explain their emotional needs, probably because they are not aware of having them or are unable to tell which they are. Even when those emotional needs are discovered, it is not obvious which technical properties of the product will elicit those desired emotions.

For many years, designers were not very interested in emotions. The focus was more on making usable products. But making products that work well and fulfill user expectations is not enough. When analyzing the products we normally use, we realize that we love some gadgets that are far from perfect, but that we just like them. Or we have a deep appreciation for a product because of the person that gave it to us as a present, or because it reminds us of the good times we had using it. These emotional aspects attached to products cannot be disregarded. The massive success of some "emotional products" in the last years, such as Apple's Ipod (first launched in 2001), confirms this tendency.

How do designers incorporate this "emotional touch" when creating a new product? They usually rely on their intuition, creativity and experience. But they also use different qualitative and quantitative methods to collect information on how products are perceived and used. Several of these methods can be grouped under the umbrella term "emotional design". One of the methods is the so-called Kansei Engineering (KE). The japonese word Kansei (感性) means sensitivity or sensibility. Simon Schütte $(2005$, p.36) proposes the following explanation of Kansei: "Kansei is an individual's subjective impression from a certain artifact, environment or situation using all the senses of sight, hearing, feeling, smell, taste and the sense of balance as well as recognition". Kansei Engineering (KE) is a method for incorporating emotions in the product development phase. The main purpose is discovering which technical parameters of a product elicit the chosen emotions. The method was first proposed by researcher Mitsuo Nagamachi in the 1970's. He had a background in psychology and medicine and was working at that time in Hiroshima University's Faculty of Engineering (Childs et al. 2003). The term Kansei Engineering was first used in 1986 by Kenichi Yamamoto, then the president of Mazda Motor (Schütte 2005). Professor Nagamachi soon adopted this term.

In the 1980's and the 1990's he created systems - which usually implied the use of computers for collecting data and statistical methods for analyzing it - for capturing users' Kansei and connecting it with product properties. Professor Nagamachi and his team collaborated with companies from many sectors during those years: automotive (Mazda, Nissan), apparel (Wacoal, Goldwin), electronic home products (Sanyo, Sharp), office machine (Fuji, Canon), and cosmetics (Shiseido), among others (Childs et al. 2003). In 1995, a paper with Mitsuo Nagamachi as sole author was published in the journal "Applied Ergonomics". This paper - 
Statistical Methods in Kansei Engineering: a Case of Statistical Engineering.

Lluís Marco-Almagro, Xavier Tort-Martorell Llabrés

"Kansei Engineering - a New Ergonomic Consumer-Oriented Technology for Product Development" (Nagamachi 1995) - can be considered as a seminal paper where Professor Nagamachi presents his proposal to the scientific community in the world.

Kansei Engineering is clearly a multidisciplinary field, where scholars with different backgrounds can provide ideas and improve methods:

- Engineers, designers, experts in ergonomics, usability and human-computer interaction, due to its deep links with industrial design.

- Neurologists, psychologists and experts in life sciences in general, because it deals with emotions and how we process them.

- Sociologists and economists, as emotional products have an impact in society both at a personal and social level.

But perhaps one of the most distinctive characteristics of Kansei Engineering is that it is based on collecting quantitative data (usually ratings made by users), as opposed to other qualitative methods used in emotional design. Once data are collected, statistical methods are commonly used to link the physical properties to the elicited perceptions. Due to this need to collect and analyze data for formulating conclusions, it seems clear that statisticians should play an important role in Kansei Engineering.

\section{A Model for Kansei Engineering Studies}

In 2002, researcher Simon Schütte from Linköpings Universitet, with a background in engineering, proposed a model for developing Kansei Engineering studies in his licentiate thesis. The model was further developed after a stay in Japan working with founder Mitsuo Nagamachi and his colleagues (professors Ishihara and Nishino among others). The model, together with a description of the idea behind Kansei Engineering, was explained in a 2004 paper co-authored by Simon Schütte, Jörgen Eklund and Jan Axelsson from Linköpings Universitet, together with founder Mitsuo Nagamachi (Schütte et al. 2004). This model systematizes the procedure and is a milestone in the effort of translating the ideas of Professor Nagamachi to the Western World.

Figure 1 shows the steps in the proposed model and are briefly described below:

- Choosing the product domain: The product domain is defined. This means not only choosing the product that will be the protagonist of the study, but also the target group for the product. For example, the product domain could be analogue watches to be used by middle aged women.

- Spanning the semantic space: Words that emotionally describe the product (called Kansei words) are collected from different sources. The initial set of words is reduced either using affinity diagrams or multivariate techniques such as cluster analysis. The output from this step is a list with all the Kansei words that will be used in the study. Examples of Kansei words for the watches could be modern, elegant, comfortable... 


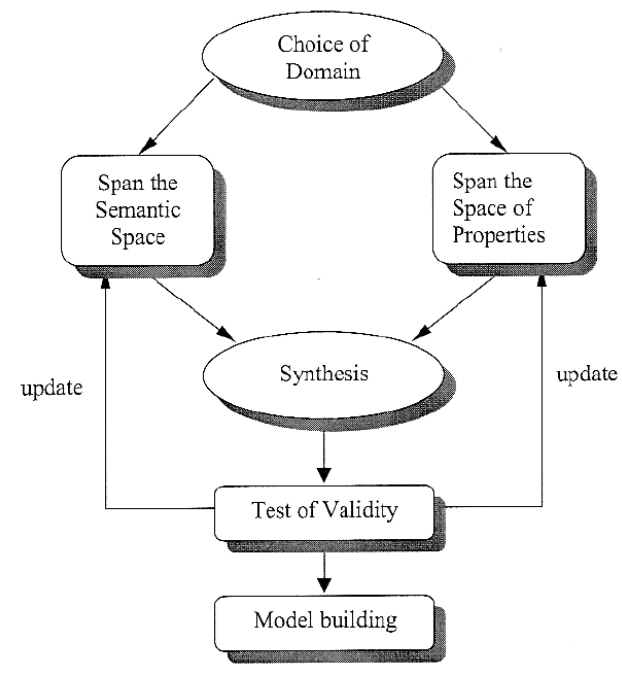

Figure 1. The original model for conducting Kansei Engineering studies, directly reproduced from the paper "Concepts, methods and tools in Kansei Engineering" (Schütte et al. 2004)

- Spanning the space of product properties: Design attributes from the studied product are collected. For each attribute, several possible values are considered. Attributes that designers think can have an effect on the emotional response are prioritized. Attributes in the example of the watches could be face color (white or brown) or face shape (rectangular or round).

A set of products (either real working products or prototypes) is prepared to be shown to participants in the study. The output from this step is the collection of products for the KE study (these products must differ in the properties just selected). In the example of the watches, four watches could be used: a rectangular watch with a white face, a rectangular watch with a brown face, a round watch with a white face and a round watch with a brown face.

Notice that design attributes used can be considered factors (with two or more levels) in a factorial design. The set of products to be shown to participants in the study can then be selected following the design matrix of a factorial design.

- Synthesis: Using statistical methods (usually linear regression models, sometimes ordinal logistic regression models), a link between product attributes (space of properties, the factors in a factorial design) and Kansei words (semantic space, the responses of the factorial design) is established. For every Kansei word, product properties are found that affect the Kansei word. In the watches example, one conclusion could be that watches with a rectangular face are perceived as elegant.

- Test of validity: Principal component analysis is used to locate the Kansei words on the first principal components. This gives an idea of which words are perceived similarly, and can be the basis for some confirmatory experiments.

- Model building: After being validated, several final models are proposed that relate the product properties with each Kansei word.

Kansei Engineering implies collecting quantitative data: usually, each participant in the study rates each shown product on each Kansei word (each response) in a five or seven point scale. This data is later used in the synthesis phase to link the space of properties with the semantic 
Statistical Methods in Kansei Engineering: a Case of Statistical Engineering.

Lluís Marco-Almagro, Xavier Tort-Martorell Llabrés

space. Several statistical methods are thus involved in Kansei Engineering (as always when data is collected and later analyzed). In particular, the following statistical techniques are mainly used in Kansei Engineering:

- Cluster analysis can be used to reduce the initial semantic space (the initial set of Kansei words) into a more manageable set of responses.

- Factorial designs are used when spanning the space of properties for choosing the set of products to be rated by participants in the data collection.

- Regression models are used to link the space of properties (the factors) and the semantic space (the responses) in the synthesis phase.

- Principal component analysis can be used to locate Kansei words (the responses) on a scatterplot with the first principal components, so showing which responses are perceived as similar.

\section{Kansei Engineering as a Case of Statistical Engineering}

Although many different statistical methods are used in Kansei Engineering, none of them are new in terms of the statistical science. The majority of them - at least in their most simple formulation - are already implemented in commonly used statistical software packages. However, we cannot consider Kansei Engineering just an example of "applied statistics", as solving a proposed problem in a statistics' textbook could be. There is something more here.

In particular, the situation fits well in many of the hallmarks defined for statistical engineering by Ronald D. Snee and Roger W. Hoerl (Snee \& Hoerl 2010): solution will satisfy a high level need, problem has high degree of complexity involving both technical and non-technical challenges, more than one statistical technique is required for solution (and also some nonstatistical techniques)...

Hoerl and Snee define statistical engineering as "the study of how to best use statistical concepts, methods and tools and integrate them with information technologies and other relevant sciences to generate improved results." (Hoerl \& Snee 2010a). It is not about developing the statistical science with new methods and tools, but on developing theories on how to better use the existing statistical tools (that is, proving what works and what does not work, and why).

Kansei Engineering is thus a good example of statistical engineering. The flowchart shown in Figure 1 (the model for conducting Kansei Engineering studies) helps in the process of finding a good solution to the problem of knowing which design properties in a product elicit the desired emotions. It would be a mistake for statisticians to state: "Kansei Engineering is not a stimulating area of research, as nothing really new from the perspective of statistical tools can be developed". Just deciding on which statistical tools are most appropriate for each step of the procedure and how to present the results in a manner easy to understand and attractive 
Statistical Methods in Kansei Engineering: a Case of Statistical Engineering.

Lluís Marco-Almagro, Xavier Tort-Martorell Llabrés

for designers are non-trivial tasks that must be done*. Probably, only statisticians can correctly perform these tasks. When studying the literature available on Kansei Engineering, one realizes that some statistical tools used are not the most adequate; even when the techniques used are appropriate, they are sometimes wrongly applied. Statisticians are thus clearly needed in KE.

As stated by Hoerl \& Snee (2010b), if statisticians do not give answers in the form of research in statistical engineering topics such as Kansei Engineering, others will do, as there is a real need to find solutions. In fact, this is already happening in the field of KE. On the contrary, the involvement of statisticians in topics such as the one presented in this paper can fortify the importance and - perhaps in the last decades - lost influence of the profession.

\section{References}

Childs, T., De Pennington, A., Rait, J., Robbins, T., Jones, K., Workman, C., Warren, S. \& Colwill, J. 2003, "Affective Design (Kansei Engineering) in Japan", A Report from a DTI International Technology Service Mission.

Hoerl, R.W. \& Snee, R.D. 2010a, "Closing the Gap," Quality Progress, May 2010, pp. 52-53.

Hoerl, R.W. \& Snee, R.D. 2010b, "Statistical Thinking and Methods in Quality Improvement: A Look to the Future," Quality Engineering, 22, pp. 119-129

Nagamachi, M. 1995, "Kansei Engineering - a New Ergonomic Consumer-Oriented Technology for Product Development", International Journal of Industrial Ergonomics, vol. 15, no. 1, pp. 3-11.

Schütte, S., Eklund, J., Axelsson, J. \& Nagamachi, M. 2004, "Concepts, methods and tools in Kansei engineering", Theoretical Issues in Ergonomics Science, vol. 5, no. 3, pp. 214.

Schütte, S. 2005, Engineering Emotional Values in Product Design: Kansei Engineering in Development, Linköping University.

Snee, R.D. \& Hoerl, R.W. 2010, "Further Explanation; Clarifying Points About Statistical Engineering," Quality Progress, December 2010, pp. 68-72.

\footnotetext{
* In fact, the idea that no new development in the statistical science can be motivated from Kansei Engineering is arguable. For example, there are still things to be done in the field of ordinal responses, the most common type of responses found in Kansei Engineering.
} 